\title{
A novel prediction model for the degree of rescue safety in mine thermal dynamic disasters based on fuzzy analytical hierarchy process and extreme learning machine
}

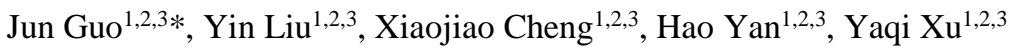 \\ ${ }^{1}$ School of Safety Science and Engineering, Xi'an University of Science and Technology, Xi'an 710054, China \\ ${ }^{2}$ Key Laboratory for Prevention and Control of Coal Fires in Shaanxi Province, Xi'an 710054, China \\ ${ }^{3}$ Key Laboratory of Western Mine and Hazard Prevention, Ministry of Education of China, Xi'an, Shaanxi, China
}

Corresponding Author Email: guojun@xust.edu.cn

https://doi.org/10.18280/ijht.360424

Received: 15 February 2018

Accepted: 7 June 2018

Keywords:
mine thermal dynamic disaster (MTDD),
fuzzy analytical hierarchy process
$(F A H P)$, extreme learning machine
$(E L M)$, degree of rescue safety

\section{INTRODUCTION}

Mine thermal dynamic disaster (MTDD) refers to a dynamic disaster related to heat, such as fire and gas explosion in coalmine production [1]. As a typical coalmine disaster, the MTDD can easily develop into a serious, fuzzy and complex situation, leading to secondary disasters and rescue difficulties. If conditions are severe, the MTDD may cause casualties to the rescuers [2-4]. Therefore, the degree of rescue safety must be evaluated in the event of an MTDD, to protect rescuers from danger and prevent the disaster from expanding.

By the weight of the evaluation index, the existing evaluation methods for safety degree can be divided into static evaluation and dynamic evaluation (a.k.a. variable weight assignment methods). The static evaluation is mainly achieved through subjective weight determination and objective weight determination [5-6]. The former can be realized by the following methods: the Delphi, analytic hierarchy process (AHP), finite state machine (FSM), capability maturity model (CMM), least-squares (LS) and chain-scoring methods [7-10], while the latter can be done through the entropy viscosity method (EVM), principal component analysis (PCA), gray correlation analysis, deviation and homogeneity method, vector similarity degree method and rough set theory [11-17].

The traditional static evaluation methods are featured by the constancy of the weight of the evaluation index, that is, the weight of the pre-set evaluation factor does not change with the actual safety of the situation in the next iteration. Hence, the evaluation result may deviate from the actual situation [18]. Compared with static evaluation methods, the dynamic evaluation methods are developed recently to assign index weights. The index weights are obtained through network training by neural networks, wavelet analysis, limit learning machines, etc. These methods output fair and objective results that adapt to the dynamic and nonlinear features of the system, because variable weight assignment can overcome the limits of the traditional static evaluation methods, mitigate the subjectivity of expert evaluations, prevent the singularity effect of the data source (i.e. the subjective simplification of the model with respect to the entity). Thanks to the advantages of variable weight assignment, the dynamic evaluation methods offer a desirable solution to the evaluation of the degree of MTDD rescue safety, in which the situation does not follow a specific law or function, the boundaries are complex and unclear, and the risks are random, fuzzy and dynamically changing [18-19]. As a result, this paper introduces the variable weight assignment to develop a dynamic evaluation model for the degree of MTDD rescue safety. To ensure reliable and fast operation, the model was further optimized by neural network methods like the fuzzy AHP (FAHP) and the extreme learning machine (ELM).

Neural networks are dynamic evaluation methods based on artificial intelligence. Despite the fruitful theoretical results and wide application, the traditional neural networks, such as back-propagation neural network (BPNN), radial basis function (RBF) neural network and support vector machine (SVM) can no longer satisfy the demand for fast recognition, owing to the growing scale, amount, uncertainty and dimensionality of the data for analysis [20]. Relying on the feedforward mechanism, the traditional neural networks consumes lots of time to adjust all parameters in training and requires repeated iterations to obtain the optimal solution. In 
addition, the weights of network neurons in different layers interact with and depend on each other [21]. Facing large and medium scale datasets, the traditional neural network algorithms are supersaturated, not to mention the difficulty in determining the optimal number of hidden layer neurons. To solve the problem, Huang et al. [22] proposed a simple, reliable and fast algorithm called the ELM, which needs only one iteration, the input weights and hidden layer offsets of random neurons to obtain the output weight and complete the network training. This algorithm has been widely adopted for data classification, pattern recognition and function approximation [23].

In view of the above, this paper combines the FAHP and an improved ELM algorithm into an integrated prediction model to quantify the degree of MTDD rescue safety in a fast and accurate manner. Firstly, a static FAHP model was constructed by the Delphi, AHP, and fuzzy comprehensive evaluation (FCE). Based on expert knowledge and experience, this static model was used to assess various MTDD rescue cases, quantify the exact degree of rescue safety and provide sample data for real-time prediction based on artificial intelligence.
Then, the improved ELM algorithm was introduced to design a dynamic prediction model for the safety of various MTDD rescue cases. The research findings shed new light on the prediction of the degree of mine rescue operations.

\section{THEORETICAL FRAMEWORK}

\subsection{The FAHP model}

The development of the MTDD is highly nonlinear and fuzzy, forming a man-machine-environment management system of multiple factors and layers. The rescue safety of such a disaster should be evaluated comprehensively against multiple attributes, which cannot be realized by a single mathematical model. Hence, this paper creates the FAHP evaluation model based on the AHP and the FCE, aiming to produce a scientific and reliable sample data of the MTDD. The workflow of the FAHP model is illustrated in Figure 1 below.

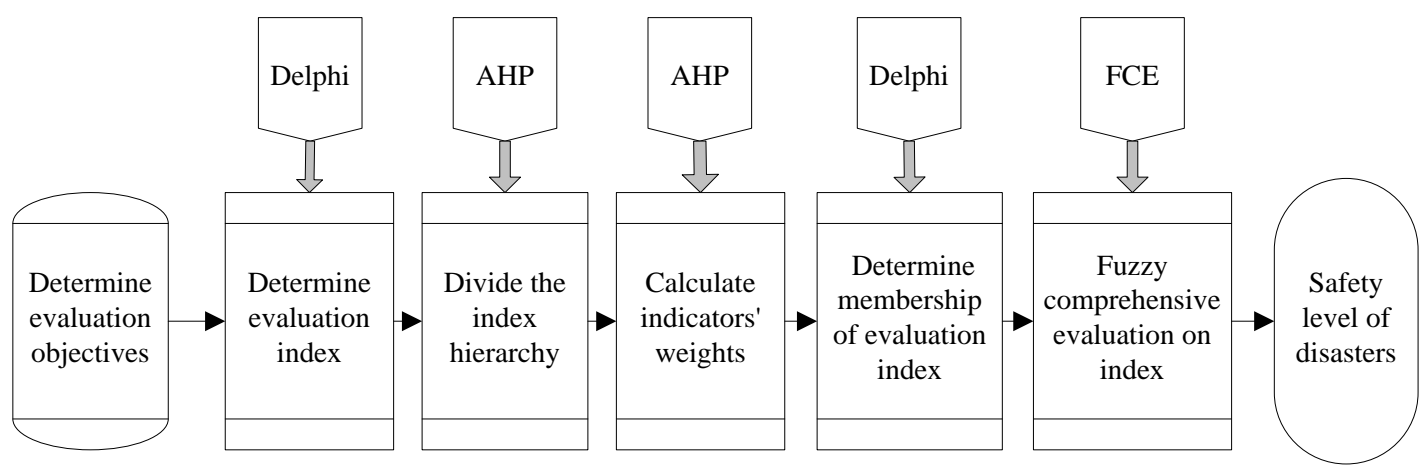

Figure 1. The workflow of the FAHP model

The FAHP model can be implemented in the following steps.

Step 1: Determining evaluation indices by the Delphi method

The evaluation indices of MTDD rescue safety were determined by the Delphi method, which fully utilizes the knowledge and experience of experts.

Step 2: Determining the index weight by the AHP

The evaluation indices were allocated into a hierarchical structure by the AHP. Then, the indices on the same layer were subjected to pairwise comparisons, and their relative importance was determined against a 9-point scale. After that, the final weight of each index was calculated.

Step 3: Determining the safety degree membership of the indices

The evaluation indices for MTDD rescue safety are partially quantitative, and thus have a certain degree of fuzziness. Therefore, the Delphi method was introduced to set up a quantitative grading standard for each index, and determine the safety degree membership of each index [24]. The safety degree was divided into five levels, namely, strongly safe, moderately safe, generally safe, moderately dangerous and strongly dangerous.

Step 4: Fuzzy comprehensive evaluation

The index set $U$ was split into $\mathrm{S}$ discontinuous subsets, denoted as $\mathrm{U}=\left\{U_{1}, U_{2}, \cdots, U_{s}\right\}$, by the importance of each index in $U_{k}(k=1,2, \cdots, s)$, to identify the fuzzy vector of indices $A_{k}\left(a_{k 1}, a_{k 2}, \cdots, a_{k m}\right)$. For each $U_{k i}$, the membership degree $r_{i j}(i=1,2, \cdots, m ; j=1,2, \cdots, n)$ of $U_{k i}$ to $V_{i}$ was judged according to the comment set $\mathrm{V}=\left\{V_{1}, V_{2}, \cdots, V_{m}\right\}$, forming a single index evaluation matrix $\widetilde{R_{k}}$. Then, we have $\widetilde{B_{k}}=\widetilde{A_{k}} \circ \widetilde{R_{k}}=\left(b_{k 1}, b_{k 2}, \cdots, b_{k n}\right) \quad(k=1,2, \cdots, s)$.

Considering the $\mathrm{S}$ subsets on $\mathrm{U}$ as $\mathrm{S}$ singletons on $\mathrm{U}$, the weights that make up fuzzy vector $\tilde{A}=\left(a_{1}, a_{2}, \cdots, a_{s}\right)$ was determined by the importance of each $U_{k}$ in $U$.

The result $\widetilde{B_{k}}=\left(b_{k 1}, b_{k 2}, \cdots, b_{k m}\right)(k=1,2, \cdots, s)$ evaluated from $U_{k}$ can be used to form a comprehensive single index evaluation matrix:

$\tilde{R}=\left[\begin{array}{c}\tilde{B}_{1} \\ \tilde{B}_{2} \\ \vdots \\ \tilde{B}_{s}\end{array}\right]=\left[\begin{array}{cccc}b_{11} & b_{12} & \cdots & b_{1 n} \\ b_{21} & b_{22} & \cdots & b_{2 n} \\ \vdots & \vdots & \vdots & \vdots \\ b_{s 1} & b_{s 2} & \cdots & b_{s n}\end{array}\right]$

where $\tilde{B}=\tilde{A} \tilde{R}=\tilde{A}\left[\begin{array}{c}\tilde{B}_{1} \\ \tilde{B}_{2} \\ \vdots \\ \tilde{B}_{S}\end{array}\right]=\tilde{A}\left[\begin{array}{c}\tilde{A}_{1} \tilde{R}_{1} \\ \tilde{A}_{2} \tilde{R}_{2} \\ \vdots \\ \tilde{A}_{S} \tilde{R}_{S}\end{array}\right]$. The multi-layer

comprehensive results can be obtained by the above method.

\subsection{ELM-based model}

(1) ELM algorithm

The ELM is a neural network algorithm with a single hidden layer. The principle of the algorithm can be explained as (Yang, 2013): For $\mathrm{N}$ distinct training samples $\left(x_{\mathrm{i}}, t_{\mathrm{i}}\right)$, with $x_{i}=$ $\left[x_{i 1}, x_{i 2}, \cdots, x_{i n}\right]^{T} \in R^{n} \quad, \quad t_{i}=\left[t_{i 1}, t_{i 2}, \cdots, t_{i m}\right] \in R^{m}$ and 
$\mathrm{i}=1 \ldots \mathrm{N}$, there exists a random small positive number $\varepsilon$ and an activation function $\mathrm{g}: \mathrm{R} \rightarrow \mathrm{R}$ that is infinitely differentiable over any interval. Then, for any $a_{i}$ and $b_{i}$ randomly chosen from any interval of $\mathrm{R}^{\mathrm{n}}$ and $\mathrm{R}$, there exists a neural network with a single hidden layer of $l$ hidden neurons and with a hidden layer output matrix $\mathrm{H}$, which guarantees the validity of $\|\mathrm{H} \beta-\mathrm{T}\|<\varepsilon\left(\mathrm{T}=\left[\mathrm{t}_{1}, \mathrm{t}_{2}, \ldots, \mathrm{t}_{\mathrm{N}}\right]^{\mathrm{T}}\right)$.

In the ELM algorithm, if $\mathrm{g}: \mathrm{R} \rightarrow \mathrm{R}$ is infinitely differentiable, then $a_{i}$ and $b_{i}$ can take any value. In other words, $a \in R^{n}$ and $\mathrm{b} \in \mathrm{R}$ can be fixed throughout the training without any adjustment. The value of $\beta$ can be obtained by solving equation $\|\mathrm{H} \beta-\mathrm{T}\|=0$. In practice, however, distinct training samples often outnumber hidden neurons. In this case, the non-square matrix $\mathrm{H}$ may falsify $\mathrm{H} \beta=\mathrm{T}$. The smallest norm LS solution of $\beta$ can obtained as:

$\hat{\beta}=H^{\dagger} T^{T}, H^{\dagger}=\left(H^{T} H\right)^{(-1)} H^{T}$

where $\mathrm{H}^{+}$is the generalized Moore-Penrose inverse of matrix $\mathrm{H}$ [25]. Considering the requirements on MTDD rescue safety prediction, this paper adopts improved algorithm based on the incremental ELM to determine the optimal parameter values of hidden neurons. The structure and workflow of the improved ELM algorithm are presented in Figure 2 below.

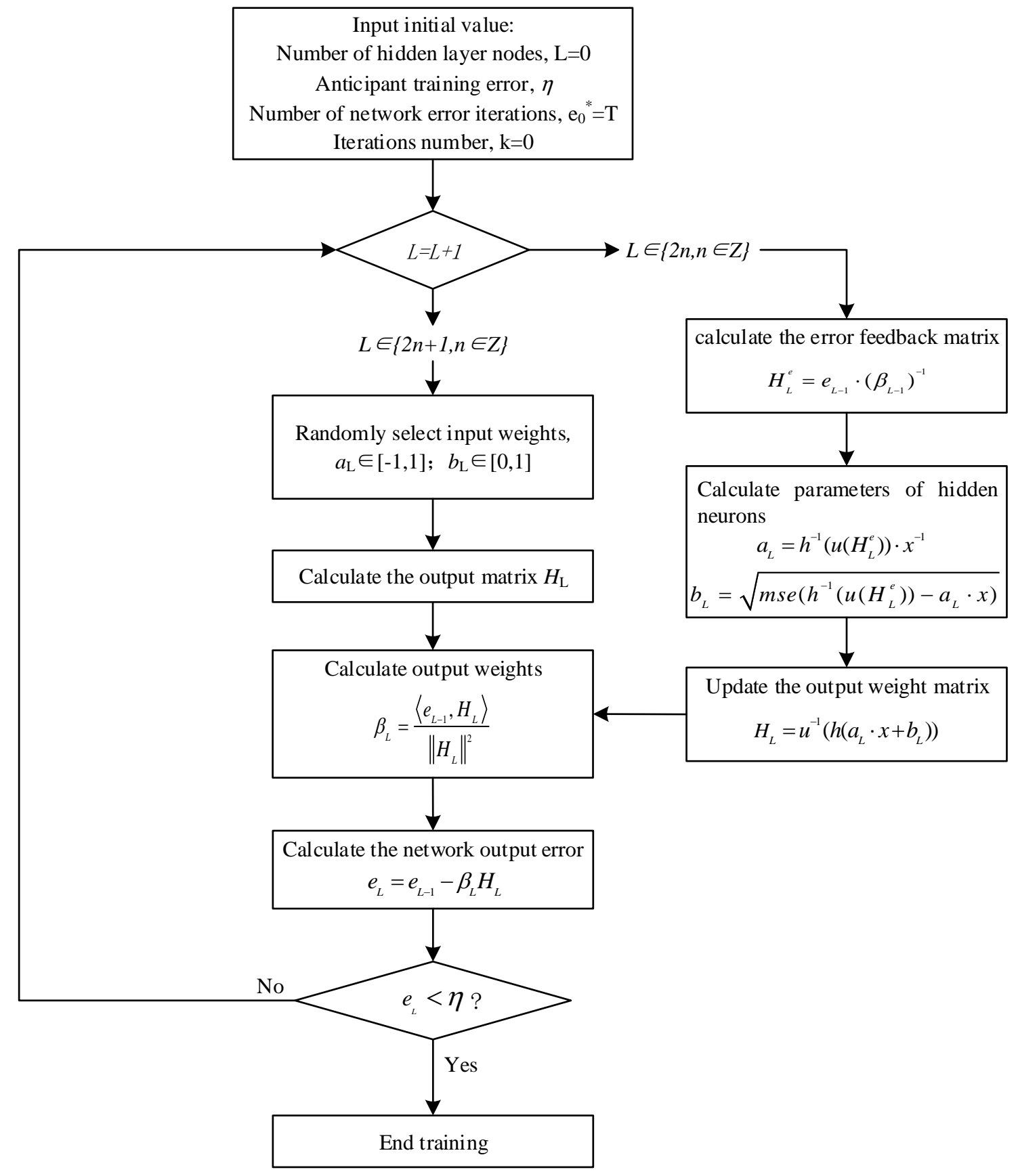

Figure 2. The structure and workflow of the improved ELM algorithm

The improved ELM calculates the parameter values of hidden neurons through the reverse transmission of the network residual, eliminating the need to search for relevant optimal parameters. In theory, the improved ELM requires two hidden neurons at most, that is, the network input error can be reduced to zero in two iterations. The simplified search process, coupled with the few number of iterations, greatly speed up the network training and save the training time [26]. 
(2) ELM prediction model and workflow

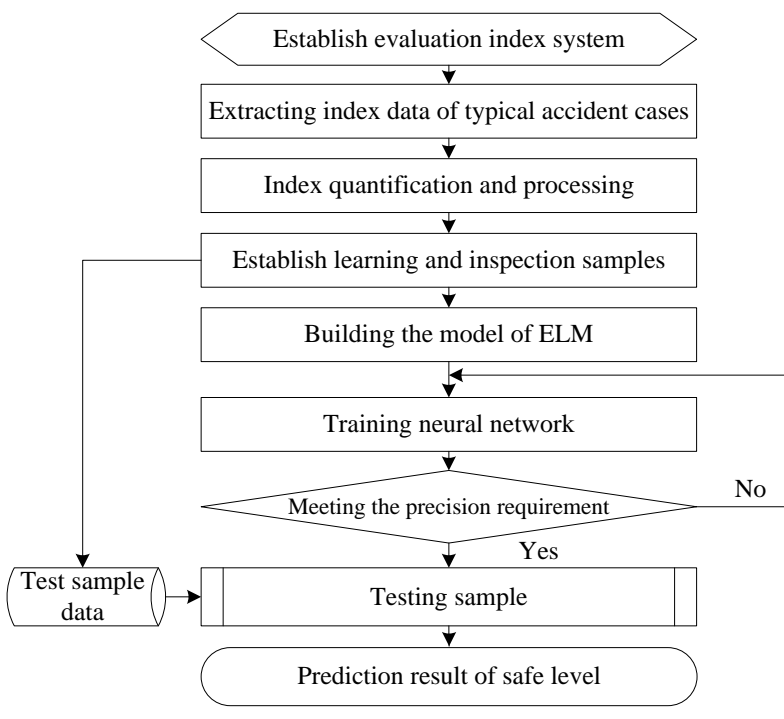

Figure 3. The workflow of the ELM prediction model
The ELM prediction model was set up as follows: the number input neurons is equal to the number of evaluation indices for MTDD safety; the inputs are the measured values corresponding to the indices; the output layer has only one neuron, which represents the safety degree; the remaining parameters were randomly assigned by the improved ELM. The workflow of the prediction model is described in Figure 3 below.

\section{FAHP-BASED SAMPLE DATA ACQUISITION}

\subsection{Evaluation index system}

In light of the features of MTDD rescue, an index system was created for evaluation of rescue safety according to the modern theories on accident cause, the Delphi and the AHP. The system consists of six primary indices and twenty secondary indices. The index system and quantification standard are shown in Table 1. The indices were quantified and ranked by the 5 -segment method, and rated by industrial experts using the Delphi method [27].

Table 1. Index system and quantification standard

\begin{tabular}{|c|c|c|c|c|c|c|c|}
\hline \multirow{2}{*}{ First index } & \multirow{2}{*}{\multicolumn{2}{|c|}{ Secondary index }} & \multicolumn{5}{|c|}{ Quantitative assignment } \\
\hline & & & 1 & 2 & 3 & 4 & 5 \\
\hline \multirow{3}{*}{$\begin{array}{l}\text { Disaster } \\
\text { location }\end{array}$} & \multicolumn{2}{|c|}{ Disaster area } & $\begin{array}{l}\text { Into the air } \\
\text { Lane }\end{array}$ & Return air lane & $\begin{array}{l}\text { Gob area } \\
\text { /sealed fire } \\
\text { zone }\end{array}$ & $\begin{array}{l}\text { Working } \\
\text { surface }\end{array}$ & Alleyway \\
\hline & \multicolumn{2}{|c|}{$\begin{array}{l}\text { Angle of slope of roadway } \\
\text { approach to disasters area } /{ }^{\circ}\end{array}$} & {$[0,8)$} & {$[8,25)$} & {$[25,35)$} & {$[35,45)$} & $\geqq 45$ \\
\hline & \multicolumn{2}{|c|}{$\begin{array}{l}\text { Disasters may affect the } \\
\text { probability of high-risk areas }\end{array}$} & Smallest & Smaller & General & Bigger & Biggest \\
\hline \multirow{7}{*}{$\begin{array}{c}\text { Roadway near } \\
\text { the disaster } \\
\text { areas }\end{array}$} & \multicolumn{2}{|c|}{ Roadway support mode } & Masonry & Anchor spray & $\begin{array}{l}\text { Hydraulic } \\
\text { monomer }\end{array}$ & $\begin{array}{c}\text { Steel } \\
\text { support }\end{array}$ & Wood support \\
\hline & \multicolumn{2}{|c|}{$\begin{array}{l}\text { Support equipment integrity rate } \\
\text { (reliability) } / \%\end{array}$} & {$[90,100)$} & {$[80,90)$} & {$[70,80)$} & {$[60,70)$} & {$[0,60)$} \\
\hline & \multicolumn{2}{|c|}{$\begin{array}{l}\text { Surrounding rock properties } \\
\text { stability }\end{array}$} & Most stable & More stable & General & Less stable & Most unstable \\
\hline & \multicolumn{2}{|c|}{$\begin{array}{c}\text { Difficulty degree of personnel } \\
\text { accessibility approach to disaster } \\
\text { area }\end{array}$} & Easiest & Easier & General & $\begin{array}{c}\text { More } \\
\text { difficult }\end{array}$ & Hardest \\
\hline & \multicolumn{2}{|c|}{ Retreat route exit number } & 3 & 1 & 1 & 0 & 3 \\
\hline & \multicolumn{2}{|c|}{ Roof fall cases } & $\begin{array}{c}\text { Nothing } \\
\text { serious }\end{array}$ & Less serious & General & $\begin{array}{c}\text { More } \\
\text { serious }\end{array}$ & The worst \\
\hline & \multicolumn{2}{|c|}{ Roadway visibility } & Clearest & Clearer & General & Less clear & Most unclear \\
\hline \multirow{2}{*}{$\begin{array}{l}\text { Roadway } \\
\text { temperature }\end{array}$} & \multicolumn{2}{|c|}{ Affected area temperature $/{ }^{\circ} \mathrm{C}$} & {$[20,30)$} & {$[30,40)$} & {$[40,50)$} & {$[50,55)$} & $\geq 55$ \\
\hline & \multicolumn{2}{|c|}{ Heating rate $/\left({ }^{\circ} \mathrm{C} \cdot \min ^{-1}\right)$} & {$[0,0.25)$} & {$[0.25,0.5)$} & {$[0.5,0.75)$} & {$[0.75,1)$} & $\geq 1$ \\
\hline \multirow{3}{*}{$\begin{array}{l}\text { Disaster area } \\
\text { gas situation }\end{array}$} & \multirow{2}{*}{$\begin{array}{l}\text { Gas concentration of } \\
\text { disaster area } / \text { vol } \%\end{array}$} & Methane & $<5$ & $<5$ & $>16$ & {$[5 \sim 16]$} & {$[5 \sim 16]$} \\
\hline & & Oxygen & $<12$ & $>12$ & $\begin{array}{l}\text { arbitrary } \\
\text { value }\end{array}$ & $<12$ & $>12$ \\
\hline & \multicolumn{2}{|c|}{ Mine gas classification } & Low gas & -- & High gas & -- & $\begin{array}{l}\text { Gas-outburst } \\
\text { mine }\end{array}$ \\
\hline \multirow{3}{*}{$\begin{array}{l}\text { Ventilation } \\
\text { system } \\
\text { conditions }\end{array}$} & \multicolumn{2}{|c|}{ Structure intact ratio } & Best & Good & General & Weak & Worst \\
\hline & \multicolumn{2}{|c|}{ Fan operation } & Best & Good & General & Weak & Worst \\
\hline & \multicolumn{2}{|c|}{$\begin{array}{c}\text { Ventilation ratio of supply and } \\
\text { demand } / \%\end{array}$} & $\geqq 95$ & {$[0.8,0.95)$} & {$[0.65,0.8)$} & {$[0.5,0.6)$} & {$[0,0.6)$} \\
\hline \multirow{3}{*}{ Fire situation } & \multicolumn{2}{|c|}{ Fire source characteristics } & -- & $\begin{array}{l}\text { Instantaneous } \\
\text { fire source }\end{array}$ & -- & -- & $\begin{array}{l}\text { Continuous } \\
\text { fire source }\end{array}$ \\
\hline & \multicolumn{2}{|c|}{$\begin{array}{l}\text { Possibility of electronic equipment } \\
\text { explosion }\end{array}$} & Impossible & Less likely & General & $\begin{array}{l}\text { More } \\
\text { likely }\end{array}$ & Possibly great \\
\hline & \multicolumn{2}{|c|}{ Fire size and feature } & $\begin{array}{l}\text { No smoke, no } \\
\text { open flame }\end{array}$ & $\begin{array}{l}\text { Smoke, no open } \\
\text { flame }\end{array}$ & Open flame & $\begin{array}{l}\text { Larger } \\
\text { open } \\
\text { flame }\end{array}$ & Uncontrolled \\
\hline
\end{tabular}




\subsection{Safety classification}

As shown in Table 2, the safety degree was divided into five levels, namely, strongly safe, moderately safe, generally safe, moderately dangerous and strongly dangerous. Table 2 shows the classification standard.

Table 2. Classification standard of safety degree

\begin{tabular}{cccccc}
\hline Level & 1 & 2 & 3 & 4 & 5 \\
\hline $\begin{array}{c}\text { Criteri } \\
\text { a range }\end{array}$ & {$[1,1.8]$} & $(1.8,2.6]$ & $(2.6,3.4]$ & $(3.4,4.2]$ & $(4.2,5]$ \\
$\begin{array}{c}\text { Safety } \\
\text { level }\end{array}$ & $\begin{array}{c}\text { Strongl } \\
\text { y safe }\end{array}$ & $\begin{array}{c}\text { Moderatel } \\
\text { y safe }\end{array}$ & $\begin{array}{c}\text { Generall } \\
\text { y safe }\end{array}$ & $\begin{array}{c}\text { Moderatel } \\
\text { dangerous }\end{array}$ & $\begin{array}{c}\text { Strongly } \\
\text { dangerou } \\
\mathrm{s}\end{array}$ \\
\hline
\end{tabular}

\subsection{Sample data acquisition}

To verify the accuracy of our model, sixty sets of data on over twenty coal mine MTDD rescue cases were collected, including fires, gas explosions and thermal dynamic plant failures. The collected data can demonstrate disaster relief situation in a comprehensive manner, because the MTDDs differ greatly in gas content and outburst condition, and involve various areas (e.g. workface, driving head and closed fire zone).

The case samples were processed under the established index system and the quantification standard, and the safety degrees of 60 samples were obtained through static FAHP evaluation. Since the sample data reflect the actual rescue situation in each case, the evaluation results were sufficiently reliable to serve as the ELM sample data for dynamic prediction. The prediction model was trained by 50 sets of data and tested by 10 sets, which were created by Guo (2016).

\section{SIMULATION OF ELM-BASED DYNAMIC PREDICTION}

\subsection{MATLAB simulation}

The ELM-based dynamic prediction model has three layers, an input layer, a hidden layer and an output layer (Figure 4).

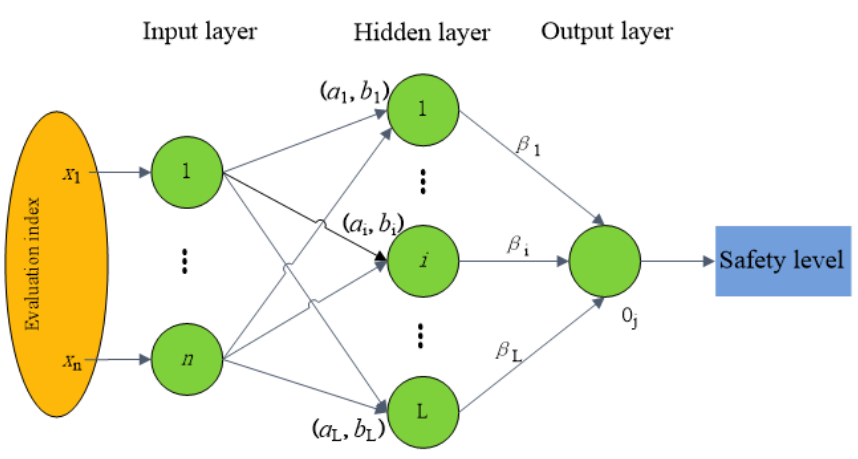

Figure 4. Network structure of improved ELM

The MTDD rescue safety evaluation system determines the safety degrees through comprehensive consideration of 21 factors, yielding one final safety degree. To make the samples more realistic, methane and oxygen levels were regarded as two independent indices during the network training. Therefore, in the ELM dynamic prediction model, the number of input neurons $n$ equals that of indices for rescue safety evaluation (i.e. $\mathrm{n}=21$ ), the number of hidden neurons needs no pre-setting, while the number of output neurons was set to 1 . The output of the neuron is the safety degree of the rescue operation. Taking the sigmoid function as the transfer activation function, the other parameters in the network need no pre-setting, as they can be automatically calculated by the function.

The proposed model was trained and simulated on Matlab R2015a. The prediction accuracy and generalization ability were measured by the test accuracy (TA) and the root mean square root (RMSE) below:

$T A=\frac{\sum_{i=1}^{m} x_{i}}{N \times m}$

$R M S E=\sqrt{\frac{\sum_{i=1}^{N}\left(y_{i}-t_{i}\right)^{2}}{N}}$

where $x_{i}$ is the number of samples correctly predicted in the ith test $(\mathrm{i}=1,2,3, \ldots, \mathrm{m} \in \mathrm{R} ; \mathrm{m}$ is the total number of tests); $\mathrm{N}$ is the number of test samples; $y_{i}$ is the $\mathrm{i}$-th sample $(\mathrm{i}=1,2$, $3, \ldots \mathrm{N} \in \mathrm{R}) ; t_{i}$ is the expected output of the $\mathrm{i}$-th sample network $(i=1,2,3, \ldots \mathrm{N} \in \mathrm{R})$.

\subsection{Analysis of simulation results}

The number of hidden neurons changed throughout the network training, for their parameters are randomly assigned. To verify the reliability of the prediction results, the evaluation tests were divided into 10 groups, each of which has 10 consecutive tests. The mean value of each group was taken as the final output. The test results are presented in Figures 5 7 below. Among them, Figure 5 compares the mean values of the ten groups with the real values, Figure 6 provides the RMSE of each test group, and Figure 7 compares the predicted values of the ten groups with the real values.

The simulation results show that only 3 out of the 100 tests failed to yield a safety degree consistent with the true value, putting the prediction accuracy at $97 \%$. The safety degree of individual samples was not predicted correctly in network training evaluation, but the mean value was very close to the true value. Hence, several sets of network trainings should be combined and their results be averaged as the result in actual prediction tasks. The simulation proves the good stability and generalization ability of the proposed model in the prediction of MTDD rescue safety.

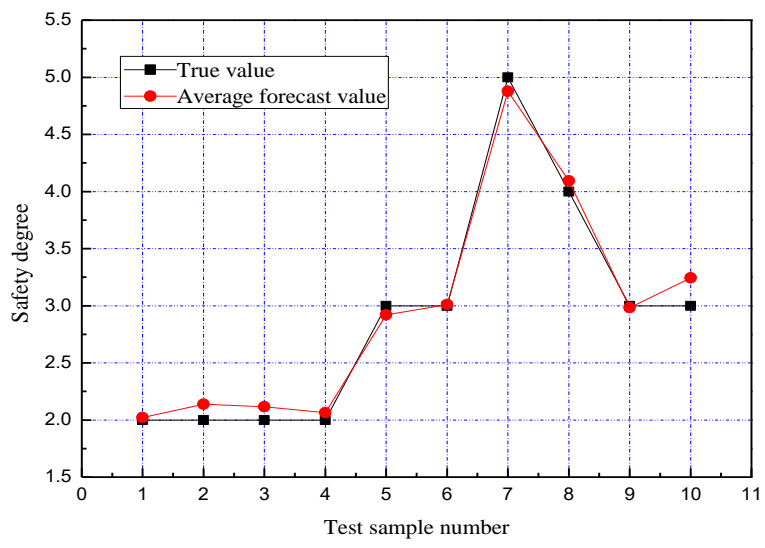

Figure 5. Comparison between the mean values of the ten groups and the real values 


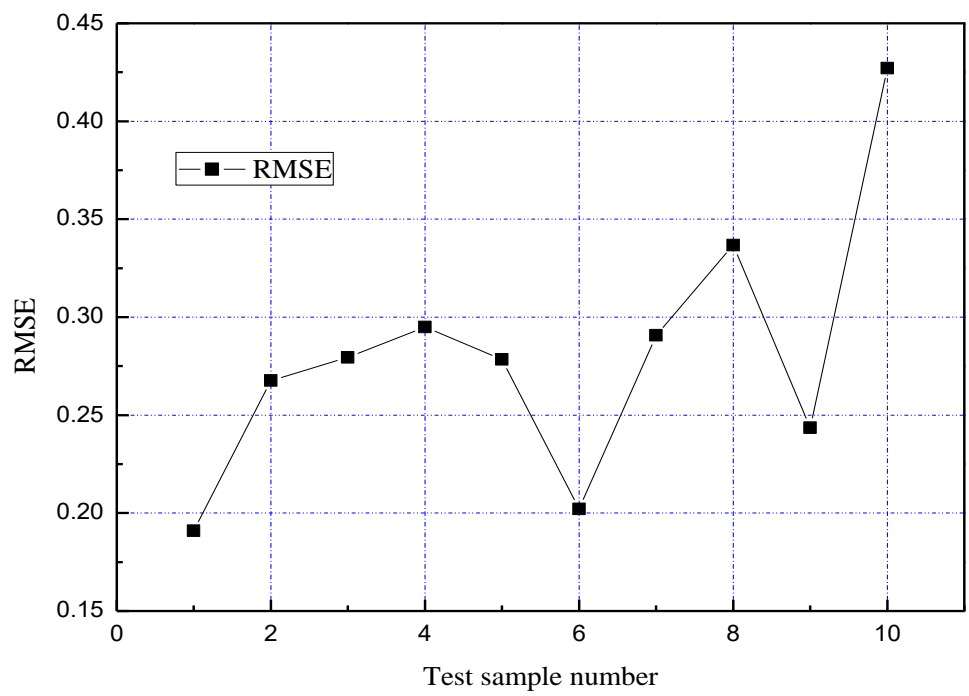

Figure 6. The RMSE of each test group

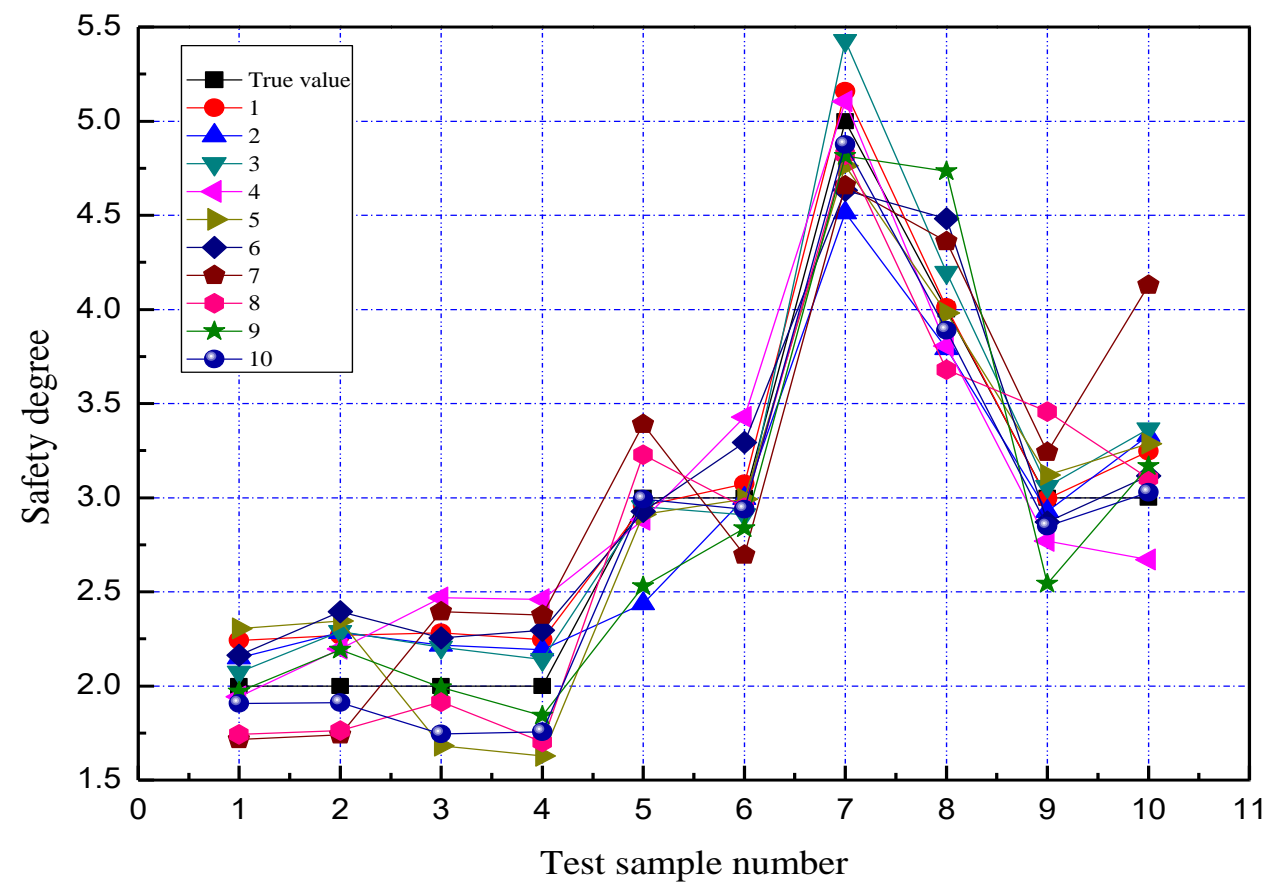

Figure 7. Comparison between the predicted values of the ten groups and the real values

\section{CONCLUSION AND DISCUSSIONS}

For accurate evaluation of the degree of MTDD rescue, this paper establishes a static FAHP comprehensive evaluation model based on the AHP and the FCE, and employs it to provide quantitative and reliable rescue sample data for the ELM-based prediction. After that, the improved ELM algorithm was introduced to set up a dynamic ELM-based prediction model. The simulation results show that the prediction model can predict the MTDD rescue safety in an accuracy and stable manner.

The ELM algorithm, a neural network with a single hidden layer, overcomes the supersaturation and the difficulty in determining the optimal number of hidden neurons, which are common problems of traditional feedforward neural network algorithms. This algorithm can change the neural network parameters dynamically, extract the intrinsic relationships and regularity of sample data rapidly and effectively, and adapt to the dynamic changes in the features of MTDDs. These unique attributes guarantee the prediction accuracy, reliability and applicability of our model.

Of course, our model still has some limitations. For example, the model can characterize the changes in MTDDs excellently and capture the variation in the importance of all indices, but cannot track the dynamic changes in a disaster over time. Thus, the accuracy and applicability of our dynamic prediction model will be further improved in future research.

\section{ACKNOWLEDGMENTS}

This work was supported financially by the following funds: National Key R\&D Program of China (2018YFC0808201); China Postdoctoral Science Foundation (2017M623209); Special scientific research project of Shaanxi Provincial Education Department (17JK0495); Natural Science Basic Research Program of Shaanxi (2018JQ5080; 2018JM5009). 


\section{REFERENCES}

[1] Wang HY, Wang BJ. (2010). Mine thermal dynamic disaster science. Coal Industry Press, Beijing.

[2] Wen H. (2014). Emergency rescue in coal mine accident China University of Mining and Technology Press, Xuzhou.

[3] Li B, Deng J, Xiao Y, Zhai XW, Shu CM, Gao W. (2018). Heat transfer capacity of heat pipes: An application in coalfield wildfire in China. Heat and Mass Transfer 54(6): 1755-1766. http://doi.org/10.1007/s00231-017-2262-6

[4] Deng J, Li B, Xiao Y, Ma L, Wang CP. (2017). Combustion properties of coal gangue using thermogravimetry-Fourier transform infrared spectroscopy. Applied Thermal Engineering 116: 244252.

http://doi.org/10.1016/j.applthermaleng.2017.01.083

[5] Wen H, Guo J, Jin YF, Zhang Z, Wang T, Liu WY. (2016). The present situation and trend of research on safety evaluation of disaster emergency rescue for China coal mine. Safety in Coal Mines 47(3): 172-178. http://doi.org/10.13347/j.cnki.mkaq.2016.03.047

[6] Zhao ZF, Wen H, Guo J. (2015). Comprehensive forecast of coal and gas outburst based on multiple methods. Safety in Coal Mines 46(11): 160-163.

[7] Xia XG, Huang QX. (2007). Application of AHP in determining weight of factors of capability of top coal caving. Journal of China Coal Society 32(10): 51-54. http://doi.org/10.1007/s10800-006-9244-6

[8] Cheng WM, Zhou G, Wang G. (2010). Evaluation method of miners' safety behavior based on gray-fuzzyimproving momentum BP algorithm. Journal of China Coal Society 35(01): 101-105.

[9] Kors JA, Bemmel JH. (1989). The Delphi method: a review of its application in medicine. The Netherlands press, Netherlands.

[10] Saaty TL. (1980). The Analytic Hierarchy Process. Mcgraw-Hill, New York.

[11] Tao JC, Wu JM. (2001). New study on determining the weight of index in synthetic weighted mark method. Systems Engineering-theory \& Practice 21(8): 78-96.

[12] Su BX, Zhang JL, Che XM. (2013). Performance evaluation of pulverized coal injection of blast furnace based on principle component analysis. Journal of China Coal Society 38(12): 2234-2240.

[13] Shi SL, Li RQ. (2010). Research and application of AHPGT model of gas explosion accident evolution risk assessment in coal mine. Journal of China Coal Society 35(07): 1137-1141. http://doi.org/10.1016/S18763804(11)60004-9

[14] Hwang CL, Yoon KS. (1981). Multiple Attribute decision making. Springer, Berlin, Heidelberg. http://doi.org/10.1007/978-3-642-48318-9
[15] Deng JL. (1982). Control problems of grey system. System and Control Letter 1(5): 288-194. http://doi.org/10.1016/S0167-6911(82)80025-X

[16] Zhao ZF, Wen H, Gao WX, Guo J. (2016). Data mining and knowledge decision in the integrity management of long-distance pipeline. Journal of Xi'an Shiyou University (Natural Science Edition) 31(4): 109-114. http://doi.org/10.3969/j.issn.1673-064X.2016.04.019

[17] Sun Q, Ouyang J. (2015). Hesitant fuzzy multi-attribute decision making based on topsis with entropy-weighted method. Management Science \& Engineering 9(3): 1-6. http://doi.org/10.1016/j.knosys.2013.05.011

[18] Guo J. (2016). Safety evaluation and dynamic prediction for the rescue operation after mine thermo dynamic disasters. Xi'an University of Science and Technology, Xi'an.

[19] Liang ZH, He WD. (2015). Research of supplier evaluation based on syncretized technique of neural network. Mathematics in Practice and Theory 45(24): 19.

[20] Yang YM, Wang YN. (2012). Bidirectional extreme learning machine for regression problem and its learning effectiveness. IEEE Transactions on Neural Networks and Learning Systems 23(9): 1498-1505. http://doi.org/10.1109/TNNLS.2012.2202289

[21] Wang YN, Yang YM. (2011). Autonomous mobile robot navigation system designed in dynamic environment based on transferable belief model. Measurement 44(8): 1389-1405. http://doi.org/10.1016/j.measurement.2011.05.010

[22] Huang GB, Zhu QY, Siew CK. (2006). Extreme learning machine: theory and applications. Neurocomputing. $70(1)$ : 489-501. http://doi.org/10.1016/j.neucom.2005.12.126

[23] Minhas R, Mohammed AA, Wu QMJ. (2010). A fast recognition framework based on extreme learning machine using hybrid object information. Neurocomputing 73(10): 1831-1839. http://doi.org/10.1016/j.neucom.2009.11.049

[24] Zhang XY, Dou SQ. (2005). The assessment of ventilation system for underground mines based on neural network. Non-ferrous Mining and Metallurgy 21(4): 11-13.

[25] Huang GB, Ding XJ, Zhou HM. (2010). Optimization method based extreme learning machine for classification. Neurocomputing 74(1-3): 155-163. http://doi.org/10.1016/j.neucom.2010.02.019

[26] Yang YM. (2013). Researches on extreme learning theory for system identification and applications. Hunan University, Changsha.

[27] Guo J, Yue NF, Jin YF, Zheng XZ. (2016). Evaluation index system for rescue safety of mine thermodynamic disasters. Safety in Coal Mine 48(7): 253-256. 